\title{
Clinical Reasoning: A 22-year-old man with progressive bilateral visual loss
}

Shi-Lin Yang, MD,* Jun Zhu, MD,* Jia-Hong Lu, MD, Zi-Gao Wang, MD, Yi-Qin Xiao, MD, Qiang Dong, MD, and Xiang Han, MD

Neurology ${ }^{\circledR}$ 2020;94:625-630. doi:10.1212/WNL.0000000000009218

\author{
Correspondence \\ Dr. Dong \\ dong_qiang@fudan.edu.cn \\ or Dr. Han \\ hansletter@163.com
}

\section{Section 1}

A 22-year-old man complained of progressive bilateral blurred vision that had developed 6 years ago. He also noted dispersed scotomas and graying of vison in both eyes, without photopsia, orbital pain, or double vision. He had not seen an ophthalmologist until he could hardly recognize people by appearance 1 week previously. Bilateral optic atrophy (figure, A) was recorded with best-corrected visual acuities of counting fingers OD and 20/400 OS. Perimetry revealed global visual field loss OD and tunnel vision OS (figure, B). He was referred to our neurology clinic, where he reported recurrent mild dull headache from age 10.

On neurologic examination, cranial nerves were normal except for bilateral diminished pupillary light reflexes and right relative afferent pupillary defect. Muscle strength, tone, deep tendon reflexes, plantar responses, and sensation were normal. Nuchal rigidity was absent. The patient was admitted.

\section{Questions for consideration:}

1. Where would you localize the lesions?

2. What is your differential diagnosis? 
Figure Fundus photographs, perimetries, brain MRI, and patient photographs
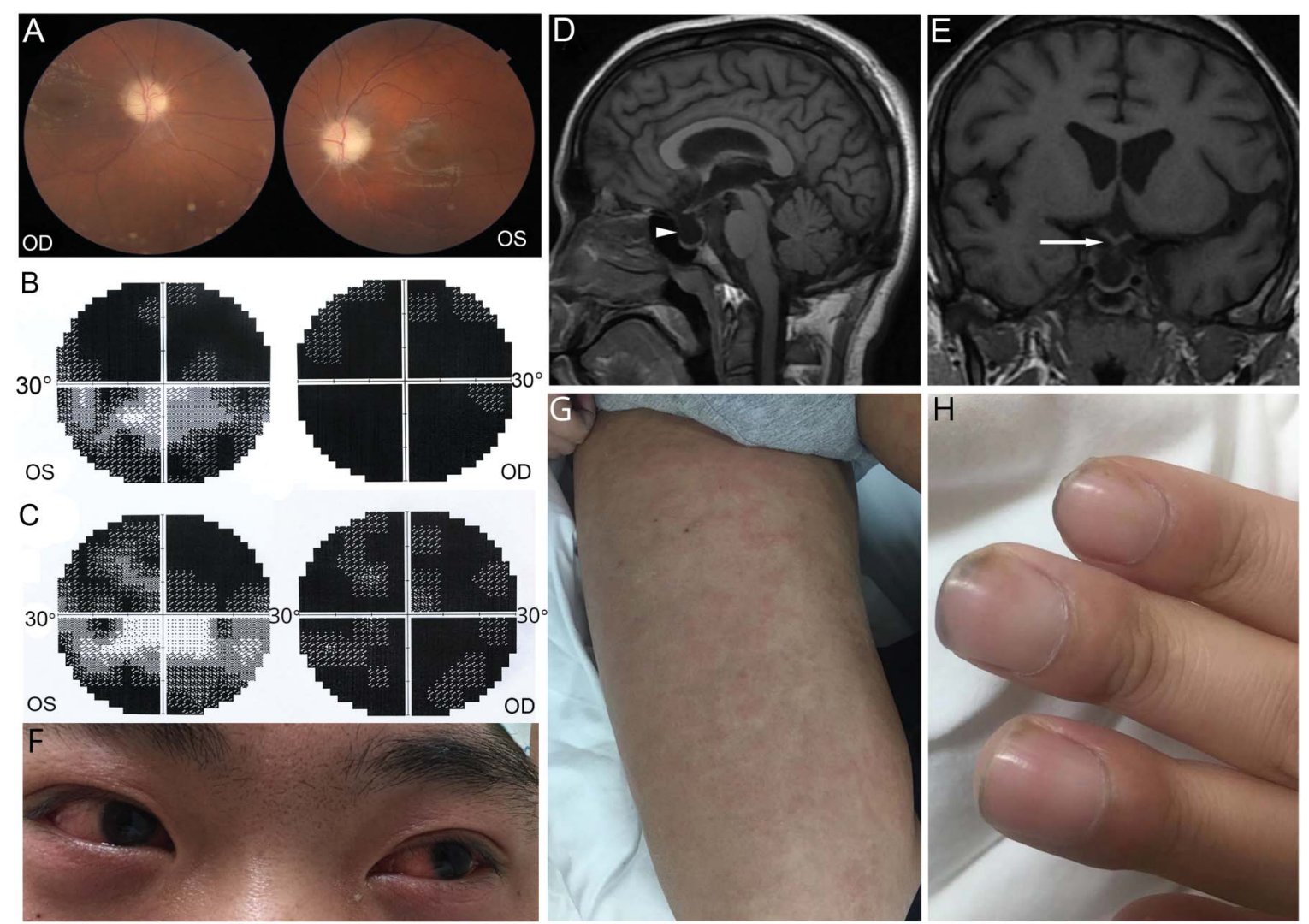

(A) Fundus photographs show bilateral optic atrophy, with optic disc pallor and blurred margin. (B) Initial perimetry demonstrates global visual field loss in the right eye and tunnel vision in the left eye. After 1 week of treatment, repeated perimetry (C) shows slight improvement. (D, E) Brain MRI shows obvious empty sella (arrowhead) and downward shift of optic chiasm (arrow). Bilateral conjunctivitis (F), urticaria-like rash eruption in the legs (G), and clubbing of fingers (H) were observed. 


\section{Section 2}

Bilateral visual impairment could originate from damage to any part of the visual pathway (from retinas to striate cortex). Pupillary light reflex deficits and optic atrophy indicates lesions affecting the anterior part of the pathway (prior to the lateral geniculate nucleus). We localized the lesions in bilateral optic nerves, chiasm, or optic tracts. Space-occupying lesions such as pituitary tumor should be ruled out first by neuroimaging. The adolescent onset and the male sex made us think of Leber hereditary optic neuropathy, but patients usually present with acute or subacute rather than chronic visual loss. Other inherited optic atrophy (e.g., OPA1-related optic atrophy), however, should be kept in mind. Idiopathic optic neuritis usually presents with acute visual loss. Anterior ischemic optic neuropathy mainly affects the elderly, especially those with risk factors, so it was unlikely to be the culprit. Laboratory tests should be ordered to search for evidence of infection, especially syphilis and tuberculosis. Toxic, traumatic, and radiation-induced optic neuropathies depend heavily on history. Combination of gradual visual impairment and chronic headache implied intracranial hypertension, which could lead to bilateral secondary optic atrophy following long-term papilledema.

Complete blood count showed white blood cells (WBC) of $15.27 \times 10^{3} / \mu \mathrm{L}$, with $79.6 \%$ neutrophils. Erythrocyte sedimentation rate $(E S R)$ was $49 \mathrm{~mm} / \mathrm{h}$ (normal $\leq 15 \mathrm{~mm}$ / h), C-reactive protein (CRP) level was higher than $72.2 \mathrm{mg} / \mathrm{L}$ (normal $\leq 8.2 \mathrm{mg} / \mathrm{L}$ ), and anti-streptolysin $\mathrm{O}$ (ASO) level was $1,050.00 \mathrm{IU} / \mathrm{mL}$ (normal $\leq 200.00 \mathrm{IU} / \mathrm{mL}$ ). Serology for HIV and syphilis was normal. Antinuclear antibodies, extractable nuclear antigen antibodies, antineutrophil cytoplasmic antibodies, and rheumatoid factor were negative.

Lumbar puncture demonstrated an elevated opening pressure of $32 \mathrm{~cm} \mathrm{H}_{2} \mathrm{O}$, elevated protein of $59.1 \mathrm{mg} / \mathrm{dL}$, elevated leukocytes of $35 / \mathrm{mm}^{3}$ with monocyte predominance, and glucose of $46.8 \mathrm{mg} / \mathrm{dL}$ (paired plasma glucose $95.4 \mathrm{mg} / \mathrm{dL}$ ). Gram stain, India ink stain, and culture of the CSF were negative. Tumor cells were not found in the CSF.

Brain MRI showed obvious empty sella and downward shift of optic chiasm (figure, D and E), consistent with prolonged intracranial hypertension. No additional abnormalities were found after gadolinium. Digital subtraction angiography demonstrated mild stenosis in bilateral transverse-sigmoid sinuses junction.

We considered intracranial hypertension from chronic aseptic meningitis as the cause of the progressive visual loss.

\section{Question for consideration:}

1. How would you investigate the aseptic meningitis?

GO TO SECTION 3 


\section{Section 3}

Aseptic meningitis refers to a medical condition that includes clinical and laboratory evidence of meningeal inflammation with negative routine bacterial cultures. It can be caused by infections, autoimmune or rheumatic diseases, malignancies, medications, and other uncommon conditions.

The high level of nonspecific serum inflammatory markers including WBC, ESR, CRP, and ASO prompted us to search for more evidence of systemic inflammatory diseases. Thorough history-taking revealed that the patient had intermittent lowgrade fever associated with rash and eye redness from age $10 . \mathrm{He}$ had mild ankle swelling in the winter between age 10 and 18 .

During this hospitalization, we observed temperature of up to $37.8^{\circ} \mathrm{C}$, bilateral conjunctivitis (figure, $\mathrm{F}$ ), urticaria-like rash eruption in the legs (figure, $\mathrm{G}$ ), as well as clubbing of fingers (figure, $\mathrm{H}$ ).

After excluding common rheumatic diseases clinically and serologically, we suspected Still disease, a rare disorder characterized by fever, rash, arthralgia/arthritis, and leukocytosis. Chronic aseptic meningitis has been reported to be a rare complication of adult-onset Still disease. ${ }^{1}$ Thus we considered the diagnosis of Still disease complicated by chronic aseptic meningitis and administered methylprednisolone $80 \mathrm{mg}$ daily IV and mannitol. The patient became afebrile with resolution of headache, rash, and conjunctivitis and normalization of the ESR and CRP levels within 1 week. After 1 week of treatment, perimetry showed slight improvement (figure, $C$ ), with visual acuities unchanged, and lumbar puncture demonstrated a pressure of $27 \mathrm{cmH}_{2} \mathrm{O}$, protein of $52.3 \mathrm{mg} / \mathrm{dL}$, and leukocytes of $5 / \mathrm{mm}^{3}$.

Although immunosuppressant therapy demonstrated efficacy, we had to exclude other etiologies, because Still disease is a diagnosis of exclusion. Because the patient had multisystem involvement from a young age, we considered genetic abnormalities, especially those related to inflammation and the immune system. Whole exome sequencing detected a heterozygous mutation of c.1049C $>\mathrm{T}$ (NM_004895.4) in NLRP3.

\section{Question for consideration:}

1. How would the genetic testing result change the diagnosis and management strategy? 


\section{Section 4}

Mutation of NLRP3 leads to cryopyrin-associated periodic syndrome (CAPS), a rare multisystem autosomal dominant inherited autoinflammatory disorder, formerly recognized as 3 unique entities-familial cold autoinflammatory syndrome (FCAS), Muckle-Wells syndrome (MWS), and neonatalonset multisystem inflammatory disease (NOMID) - also known as chronic infantile neurologic cutaneous articular (CINCA) syndrome. ${ }^{2}$ All the subtypes have episodes of fever, urticaria-like rash, red eyes, and articular and CNS involvement to varying degrees, all of which our patient had experienced. The mutation found in our patient is a missense mutation and has been reported to be pathogenic. ${ }^{3} \mathrm{He}$ had no siblings and his parents were healthy and did not have this mutation. The diagnosis was changed from Still disease to CAPS.

Steroid treatment was continued with tapering. The patient was responsive to steroids, with disappearance of fever, headache, rash, and pink eye, and gradual improvement of vision. However, these symptoms worsen once prednisone is tapered below $20 \mathrm{mg}$ daily. While the patient continues prednisone in a daily dose of $20 \mathrm{mg}$, we are seeking access to anti-interleukin (IL) -1 medications, which have been proven effective for CAPS, ${ }^{4,5}$ but are not available in the Chinese market. Genetic counseling was offered due to a 50\% chance of the patient's offspring inheriting this disease.

\section{Discussion}

The patient presented with bilateral optic atrophy, which turned out to be caused by intracranial hypertension from chronic aseptic meningitis, a neurologic complication of CAPS.

Papilledema is an important neuro-ophthalmologic sign of elevated intracranial pressure. Our patient presented with optic atrophy rather than optic disc swelling, which made the intracranial hypertension easily overlooked, especially given that the headache was not obvious. Intracranial hypertension leads to papilledema with or without impaired visual function in the early stage. If left uncontrolled, it will result in optic atrophy and blindness in the late stage. In optic atrophy secondary to papilledema, the margin is blurred (rather than sharp) and the disc grayish, as shown in the figure, A.

Mutation of NLRP3 resulted in CAPS, a rare autoinflammatory disease affecting multiple organs and systems. It can be subdivided into 3 phenotypes: FCAS, MWS, and NOMID/CINCA. The clinical features common to each of these types include recurrent fever, urticaria-like rash, arthralgia/arthritis, and conjunctivitis. Cold exposure as a trigger for these symptoms is the most notable clinical feature of FCAS. Patients with MWS, undergoing a more chronic course, often develop progressive sensorineural deafness and sometimes AA amyloidosis. ${ }^{6}$ NOMID/CINCA, the most severe type of CAPS, often presents within the first days of birth, causes persistent inflammation, and leads to prominent neurologic damage. Some patients have overlapping phenotypes. Patients with CAPS often develop symptoms early in life, even at birth. However, these symptoms can be delayed for many years, as in our case. Clubbing of fingers is a suggestive sign, although it has not been reported frequently.

Neurologic complication, an essential component of NOMID/CINCA, is not uncommon in FCAS and MWS. ${ }^{7,8}$ It includes headache, seizures, sensorineural deafness, myalgia, aseptic meningitis, papilledema, and optic atrophy. ${ }^{7,8}$ CAPS may be encountered by neurologists because it can present mainly or only with neurologic complaints. This case suggests that CAPS should be included in the differential diagnosis of chronic aseptic meningitis, especially when the patients are children or adolescents and have systemic inflammatory manifestations (e.g., fever, rash, arthralgia/arthritis) and elevated inflammatory markers.

Because of the important role of IL-1 in CAPS, the disorder can be treated effectively with anti-IL-1 therapy. Patients have achieved sustained remission of symptoms with treatment with canakinumab, an IL- $1 \beta$ monoclonal antibody, $150 \mathrm{mg}$ subcutaneously at 8 -week intervals. ${ }^{4}$ Anakinra, an IL-1 receptor antagonist, also demonstrates efficacy, but daily subcutaneous injection is required. ${ }^{5}$ Neither is available in China, in which situation long-term low-dose steroids might be necessary for severe phenotypes of CAPS.

CAPS should be considered in chronic aseptic meningitis when other features of CAPS are present. Early diagnosis and targeted therapy are crucial to prevent irreversible organ damage.

\section{Study funding}

No targeted funding reported.

\section{Disclosure}

The authors report no disclosures relevant to the manuscript. Go to Neurology.org/N for full disclosures.

Appendix Authors

\begin{tabular}{|c|c|c|}
\hline Name & Location & Contribution \\
\hline $\begin{array}{l}\text { Shi-Lin } \\
\text { Yang, } \\
\text { MD }\end{array}$ & $\begin{array}{l}\text { Department of Neurology, } \\
\text { Huashan Hospital, Fudan } \\
\text { University }\end{array}$ & $\begin{array}{l}\text { Collection and } \\
\text { interpretation of data, } \\
\text { manuscript drafting }\end{array}$ \\
\hline $\begin{array}{l}\text { Jun } \\
\text { Zhu, } \\
\text { MD }\end{array}$ & $\begin{array}{l}\text { Department of Neurology, } \\
\text { Huashan Hospital, Fudan } \\
\text { University }\end{array}$ & $\begin{array}{l}\text { Collection and } \\
\text { interpretation of data, } \\
\text { manuscript drafting }\end{array}$ \\
\hline $\begin{array}{l}\text { Jia- } \\
\text { Hong } \\
\text { Lu, MD }\end{array}$ & $\begin{array}{l}\text { Department of Neurology, } \\
\text { Huashan Hospital, Fudan } \\
\text { University }\end{array}$ & $\begin{array}{l}\text { Collection and } \\
\text { interpretation of data }\end{array}$ \\
\hline
\end{tabular}


Appendix (continued)

\begin{tabular}{lll}
\hline Name & Location & Contribution \\
\hline $\begin{array}{l}\text { Zi-Gao } \\
\text { Wang, } \\
\text { MD }\end{array}$ & $\begin{array}{l}\text { Department of Neurology, } \\
\text { Huashan Hospital, Fudan } \\
\text { University }\end{array}$ & $\begin{array}{l}\text { Collection and } \\
\text { interpretation of data }\end{array}$ \\
\hline $\begin{array}{l}\text { Yi-Qin } \\
\text { Xiao, } \\
\text { MD }\end{array}$ & $\begin{array}{l}\text { Department of Ophthalmology, } \\
\text { Huashan Hospital, Fudan }\end{array}$ & $\begin{array}{l}\text { Collection and } \\
\text { interpretation of data }\end{array}$ \\
\hline $\begin{array}{l}\text { Qiang } \\
\text { Dong, }\end{array}$ & $\begin{array}{l}\text { Department of Neurology, } \\
\text { MD }\end{array}$ & $\begin{array}{l}\text { University } \\
\text { revision of manuscript }\end{array}$ \\
\hline $\begin{array}{l}\text { Xiang } \\
\text { Han, }\end{array}$ & $\begin{array}{l}\text { Department of Neurology, } \\
\text { Muashan Hospital, Fudan }\end{array}$ & $\begin{array}{l}\text { Supervision, critical } \\
\text { revision of manuscript }\end{array}$ \\
\hline
\end{tabular}

\section{References}

1. Akkara Veetil BM, Yee AH, Warrington KJ, Aksamit AJ Jr, Mason TG. Aseptic meningitis in adult onset Still's disease. Rheumatol Int 2012;32:4031-4034.

2. Booshehri LM, Hoffman HM. CAPS and NLRP3. J Clin Immunol 2019;39:277-286.

3. Levy R, Gerard L, Kuemmerle-Deschner J, et al. Phenotypic and genotypic characteristics of cryopyrin-associated periodic syndrome: a series of 136 patients from the Eurofever Registry. Ann Rheum Dis 2015;74:2043-2049.

4. Kone-Paut I, Lachmann HJ, Kuemmerle-Deschner JB, et al. Sustained remission of symptoms and improved health-related quality of life in patients with cryopyrinassociated periodic syndrome treated with canakinumab: results of a double-blind placebo-controlled randomized withdrawal study. Arthritis Res Ther 2011;13: R202.

5. Kone-Paut I, Galeotti C. Anakinra for cryopyrin-associated periodic syndrome. Expert Rev Clin Immunol 2014;10:7-18.

6. Muckle TJ. The "Muckle-Wells" syndrome. Br J Dermatol 1979;100:87-92.

7. Kitley JL, Lachmann HJ, Pinto A, Ginsberg L. Neurologic manifestations of the cryopyrin-associated periodic syndrome. Neurology 2010;74:1267-1270.

8. Kilic H, Sahin S, Duman C, et al. Spectrum of the neurologic manifestations in childhood-onset cryopyrin-associated periodic syndrome. Ann Rheum Dis Epub 2019 Mar 28.

\section{Register for 2020 AAN Sports Concussion Conference}

Join us for a weekend of the most cutting-edge scientific updates and best practices for the prevention, diagnosis, and management of sport-related concussion this July 17-19 in Minneapolis, MN. Visit AAN.com/SCC to learn more.

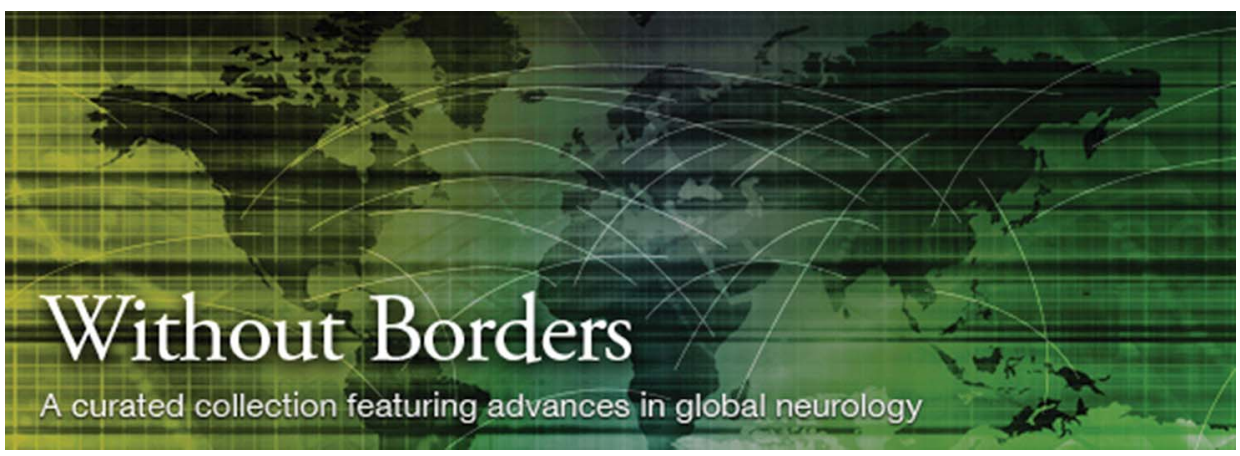

\section{Without Borders - A curated collection featuring advances in global neurology}

This Neurology ${ }^{\circledR}$ special interest website is the go-to source for tracking science and politics of neurology beyond the United States, featuring up-to-the-minute blogs, scholarly perspectives, and academic review of developments and research from Neurology journals and other sources. Curated by Gretchen L. Birbeck, MD, MPH.

Expand your world view at Neurology.org/woborders. 


\section{Neurology}

\section{Clinical Reasoning: A 22-year-old man with progressive bilateral visual loss}

Shi-Lin Yang, Jun Zhu, Jia-Hong Lu, et al.

Neurology 2020;94;625-630 Published Online before print March 9, 2020

DOI 10.1212/WNL.0000000000009218

\section{This information is current as of March 9, 2020}

\section{Updated Information \&} Services

\section{References}

Subspecialty Collections

Permissions \& Licensing

Reprints including high resolution figures, can be found at: http://n.neurology.org/content/94/14/625.full

This article cites 7 articles, 2 of which you can access for free at: http://n.neurology.org/content/94/14/625.full\#ref-list-1

This article, along with others on similar topics, appears in the following collection(s):

All Immunology

http://n.neurology.org/cgi/collection/all_immunology

Optic nerve

http://n.neurology.org/cgi/collection/optic_nerve

Other neurocutaneous disorders

http://n.neurology.org/cgi/collection/other_neurocutaneous_disorders

Visual loss

http://n.neurology.org/cgi/collection/visual_loss

Information about reproducing this article in parts (figures,tables) or in its entirety can be found online at:

http://www.neurology.org/about/about_the_journal\#permissions

Information about ordering reprints can be found online:

http://n.neurology.org/subscribers/advertise

Neurology ${ }^{\circledR}$ is the official journal of the American Academy of Neurology. Published continuously since 1951, it is now a weekly with 48 issues per year. Copyright () 2020 American Academy of Neurology. All rights reserved. Print ISSN: 0028-3878. Online ISSN: 1526-632X.

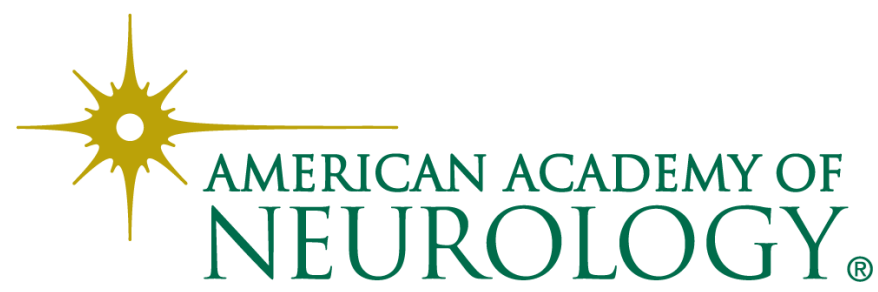

